\title{
COUPLED STATIC AND DYNAMIC BUCKLING MODELLING OF THIN-WALLED STRUCTURES IN ELASTIC RANGE REVIEW OF SELECTED PROBLEMS
}

\author{
Zbigniew KOŁAKOWSKI", Andrzej TETER ${ }^{* *}$ \\ *Department of Strength of Materials, K12, Lodz University of Technology, ul. Stefanowskiego 1/15, 94-024 Lodz, Poland \\ ${ }^{*}$ Department of Applied Mechanics, Lublin University of Technology, ul. Nadbystrzycka 36, 20-618 Lublin, Poland \\ zbigniew.kolakowski@p.lodz.pl, a.teter@pollub.pl
}

received 30 September 2015, revised 12 May 2016, accepted 17 May 2016

\begin{abstract}
A review of papers that investigate the static and dynamic coupled buckling and post-buckling behaviour of thin-walled structures is carried out. The problem of static coupled buckling is sufficiently well-recognized. The analysis of dynamic interactive buckling is limited in practice to columns, single plates and shells. The applications of finite element method (FEM) or/and analytical-numerical method (ANM) to solve interaction buckling problems are on-going. In Poland, the team of scientists from the Department of Strength of Materials, Lodz University of Technology and co-workers developed the analytical-numerical method. This method allows to determine static buckling stresses, natural frequencies, coefficients of the equation describing the post-buckling equilibrium path and dynamic response of the plate structure subjected to compression load and/or bending moment. Using the dynamic buckling criteria, it is possible to determine the dynamic critical load. They presented a lot of interesting results for problems of the static and dynamic coupled buckling of thin-walled plate structures with complex shapes of cross-sections, including an interaction of component plates. The most important advantage of presented analytical-numerical method is that it enables to describe all buckling modes and the post-buckling behaviours of thin-walled columns made of different materials. Thin isotropic, orthotropic or laminate structures were considered.
\end{abstract}

Key words: Interaction, Buckling, Thin-Walled Structures, FEM, Analytical-Numerical Method, Review

\section{COUPLED BUCKLING OF THIN-WALLED STRUCTURES}

The theory of coupled or interactive buckling of thin walled structures has been already developed widely for over sixty years. Thin-walled structures, especially plates, columns and beams, have many different buckling modes that vary in quantitative and qualitative aspects. In these cases, nonlinear buckling theory should describe all buckling modes from global (i.e., flexural, flexural-torsional, lateral, distortional and their combinations) to local and the coupled buckling as well as the determination of their load carrying capacity taking into consideration the structure imperfection. Coupling between modes occur for columns of such length where two or more eigenvalues loads of a structure are nearly identical (Fig. 1). The local buckling takes place for the short columns. On the other hand, the long columns are subject to global buckling.

The concept of coupled or interactive buckling involves the general asymptotic nonlinear theory of stability. Among all versions of the general nonlinear theory, the Koiter theory of conservative systems (Koiter, 1976; van der Heijden, 2009) is the most popular one, owing to its general character and development, even more so after Byskov and Hutchinson (1997) formulated it in a convenient way. The details descriptions of this method can be found in the monographs: van der Heijden (2009), Thompson and Hunt (1973) or Kubiak (2013). Applicability of an asymptotic expansion for elastic buckling problems with mode interaction was discussed in many papers, for instance: Tvergaard (1973a, 1973b), Koiter and Pignataro (1974), Byskov (1979,
1988), Sridharan (1983), Benito and Sridharan (1985a, 1985b), Pignataro and Luongo (1985, 1987a, 1987b), Casciaro et al. (1998), Goltermann and Mollman (1989a, 1989b), Garcea et al. $(1999,2009)$, Barbero et al. (2014).

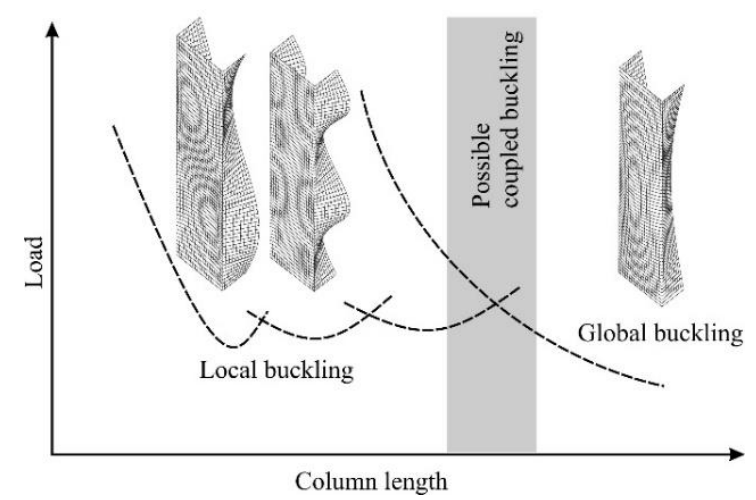

Fig. 1. Buckling modes vs. column length

The theory is based on asymptotic expansions of the postbuckling path and is capable of expanding the potential energy of the system in a series relative to the amplitudes of linear modes near the point of bifurcation. This theory is capable of considering many different buckling modes. The two uncoupled modes are symmetric and stable, but on coincidence they are found to give rise to a symmetric unstable mixed form (Fig. 2). The unstable coupled path will branch off the lower of the two uncoupled paths. 
The coupled post-buckling path can be important in continuous systems and it have an important effect on the type of instability which occurs. It enables determination of post-buckling equilibrium paths for the imperfect structure and to determine on them secondary bifurcation points or/and the limit point. If one takes into account the second order approximation, one can determine the limit load capacity of a structure in the elastic range. An assumption of one of the "engineering" hypotheses of load carrying capacity allows for determination of the approximate estimation of load carrying capacity for the elastic-plastic range. This approach provides a lower bound of this load carrying capacity.
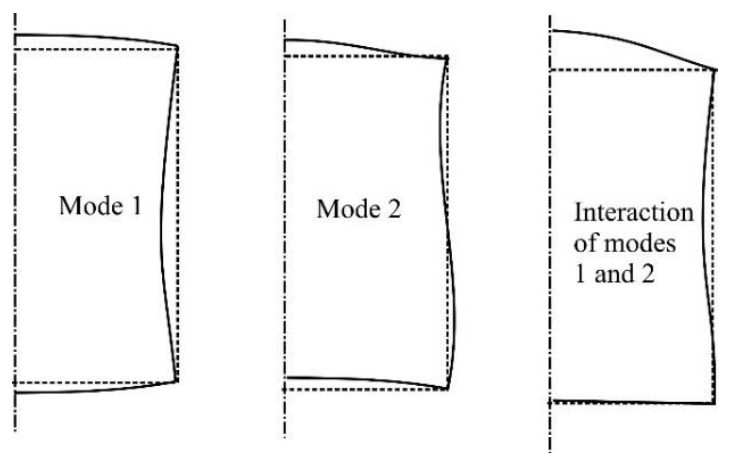

Fig. 2. Coupled buckling of two modes (view of cross sections) (Sridharan, 1983)

Although the problem of static coupled buckling can be treated as sufficiently well-recognized. Many scientists dealt with this problem, for instance: Sridharan and co-workers (1983, 1985a, 1985b, 1985c, 1986, 1988), Goltermann and Mollman (1989a, 1989b), Manevich (1981, 1982, 1985, 1988), Kolakowski (1987a, 1987b, 1988, 1989a, 1989b, 1989c, 1993a, 1993b, 1996).

The numerical calculations carried out by Kolakowski (1987a, 1987b, 1988, 1989a, 1989b, 1989c, 1993a, 1993b, 1996) have proven that the interaction of local modes having considerably different wavelengths is either very weak or does not occur at all. Moreover, one can see that the interaction of two global modes of buckling is very weak or even does not occur at all. According to the assumptions made in Byskov and Hutchinson's (1977) theory, local buckling modes do not interact explicitly. However, the interaction occurs through the interaction of each of them with the global mode. It can be noticed that the global flexural (Euler) buckling can interact with an even number of local modes that are symmetric or antisymmetric but the global flexural-torsional mode only with pairs of symmetric and antisymmetric modes. In some cases, an improper selection of the mode, even if a few of them are considered, may lead to an overestimation of the structure load carrying capacity; also the consideration of the two-mode approach may sometimes be misleading and yield false conclusions. This can be accomplished only by means of a non-linear analysis. The consideration of displacements and load components in the middle surface of walls within the first order approximation and precise geometrical relationships enabled the analysis of all possible buckling modes, including a mixed buckling. In thinwalled structures of open cross-sections, owning to their low rigidity, it is necessary to consider distortional deformations. The above factors have even led to the consideration of an interaction of a few modes - two global and some local ones. If the analysis of the stability problem of thin-walled structures is restricted to the first order approximation, where the theoretical limit load is always lower than the minimum value of the bifurcational load in the linear analysis, the imperfection sensitivity can only be obtained. The determination of the post-buckling equilibrium path requires the second order approximation to be taken into account. The structures where the local buckling precedes the global one are widely used because these perfect structures can carry a load higher than that referring to the bifurcation value of the local buckling. Therefore, it is necessary to consider the second order approximation, that is to say, the fourth order components of the potential energy. In general, the stability analysis with regard to the second non-linear approximation requires the solution of boundary value problems: for the second order global, local and mixed modes.

The analysis of dynamic interactive buckling is limited in practice single plates and shells. There are known the solutions of dynamic buckling problem for columns (Budiansky, 1966a; 1966b). But there are not many solutions for plate model of thinwalled structures (Sridharan, 1984; Kolakowski, 2007; Kolakowski and Kubiak, 2007; Kubiak, 2007; Teter, 2007, 2010, 2011, Teter and Kolakowski, 2013).

Dynamic buckling or dynamic response can be treated as a reinforcement of imperfections, initial displacements or stresses in the structure through dynamic loading in such a manner that a level of the dynamic response becomes very high (Ari-Gur and Simonetta, 1997; Lindberg, 1987; Strogne, 2000). For dynamic buckling of a perfect structure due to a pulse loading, there is no exact counterpart of the static characteristic bifurcation load. When the load is low, the thin-walled structure vibrates around the static equilibrium position. On the other hand, when the load is sufficiently high, then the structure can vibrate very strongly or can move divergently, which is caused by dynamic buckling. One should not confuse this case with vibration buckling where the loads are periodic and the transverse vibration becomes unacceptably large at critical combinations of amplitude, load frequency and damping. In this case one can get parametric resonance or ordinary resonance (Lindberg, 1987; Strogne, 2000; Simitses, 1990, 2006; Virgin, 2007; Warminski and Teter, 2012).

Chapters of monographs by Simitses $(1990,2006)$ and Virgin (2007) deals with the response of structures subjected to oscillating loads, leading to, so-called, vibration buckling. The periodically changing load produces periodically changing coefficients in the mathematical model. Then, in certain frequency intervals, the trivial solution loses its stability and, the parametric resonance occurs. In such a case transverse vibrations become unacceptably large at critical combinations of amplitude, load frequency and damping. The most essential and dangerous, from the practical point of view, is the principal parametric resonance. This phenomenon appears for sufficiently small values of the axial force, when the loading frequency equals twice the natural bending frequency of the system (the column in our case). Apart from the principal also case the fundamental resonances may also appear, when the loading frequency coincides with the natural bending frequency of the column. Moreover the secondary parametric resonances may also occur. So, vibration buckling corresponds to the buckling resulting from parametric excitations. In paper by Warminski and Teter (2012), the authors deals with aspects of the dynamic behaviour of thin-walled composite column under compression load, composed of static and periodic parts. The mathematical model of the structure considers geometrical nonlinear terms which couple considered global and local buckling modes of the column. The dynamic response is investigated around the principal parametric resonances. 
In the analysis of dynamic stability of the thin walled structure under in-plane pulse loading, the following should be taken into account: shape of pulse loading, pulse duration and a magnitude of its amplitude (Kubiak, 2013; Lindberg, 1987; Strogne, 2000; Simitses, 1990, 2006; Bangash, 2009). The rectangular pulse is the most dangers (Kubiak, 2013). If the pulse duration is comparable to the period of natural vibrations, the dynamic pulse buckling occurs. If the pulse duration is longer, the problem becomes quasi-static. When the displacement growth is assessed with time for different amplitude of load, buckling occurs when the dynamic load reaches a critical value associated with a maximum acceptable deformation (strain) or stress, the magnitudes of which are defined arbitrarily. Thus, there is no perfect criterion so far for dynamic buckling and no general guidelines for the design. In the literature on this problem, various criteria concerning dynamic stability have been adopted (Kubiak, 2013; Simitses, 1990). One of the simplest is the criterion suggested by Volmir (Kubiak, 2013; Volmir, 1972).

Volmir (1972) analyzed the behaviour of a simply supported rectangular plate subjected to different pulse loads. He considered the buckling problem which can be described by a system with one degree of freedom and defined the Dynamic Load Factor as a ratio of the pulse amplitude of the critical load to the static critical load. Volmir proposed a criterion for the dynamic buckling, assuming that a loss of stability of the plate subjected to pulse load occurs when the maximum deflection of the plate is equal to the assumed constant value. Usually the critical deflection value was assumed to be equal to the thickness of the plate or half of its thickness.

The most widely used is the Budiansky-Hutchinson's criterion (Budiansky, 1966a; 1966b; Hutchinson and Budiansky, 1966), in which it is assumed that the loss of dynamic stability occurs when the displacement rate is the highest for a certain force amplitude. A dynamic load factor DLF has been defined as the quotient of the dynamic load amplitude and minimum critical stress (Kappos, 2002; Weller et al., 1989). In order to find the critical value of dynamic load factor DLFcr one should draw a graph of deflection amplitude as a function of dynamic load factor DLF (Fig. 3).

The equations of motion are solved for various load parameters to obtain the response of the system. When the motion of the system changes from small-amplitude oscillatory to largeamplitude oscillatory or becomes associated with distinctly removed positions from the undisturbed ones, the corresponding load parameter is called a dynamic critical load. Its disadvantage is an extremely large amount of computer time required to solve the equations of motion at different levels of the applied loads. In the case of uncoupled dynamic buckling, the curves suiting global modes in this graph are always unrestricted (Fig. 3b). The critical value of dynamic load factor is read off for the adopted restriction. It is worthy to add, when speaking about the local buckling mode, that in order to find critical value of dynamic load factor one has to find the point of inflection on the curve (Fig. 3a). The Budiansky-Hutchinson's criterion was used at many papers, for instance: Kolakowski and Kubiak (2007), Kubiak (2007), Teter (2007, 2010, 2011), Teter and Kolakowski (2013), Weller (1989), Hsu (1967, 1968), Tamura and Babcock (1975), Gilat and Aboudi (1995), Zhang et al. (2004), Mania (2005), Mania and KowalMichalska (2007).

Other criteria: Ari-Gur and Simonetta's criterion, KleiberKotula-Saran criterion, Kubiak criterion, Petry-Fahlbusch criterion, phase plane criterion concept have been discussed in the papers (Ari-Gur and Simonetta, 1997; Petry and Fahlbusch, 2000; Cui et al., 1999, 2002) and the monograph (Kubiak, 2013).

(a)

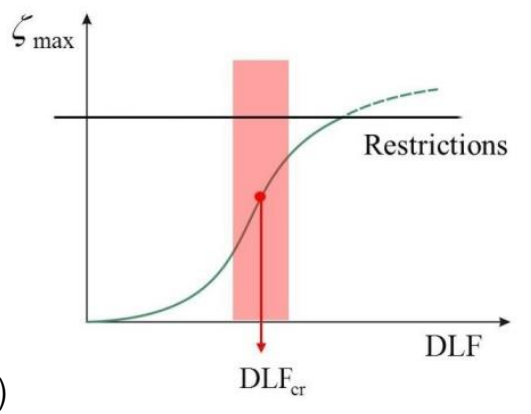

(b)

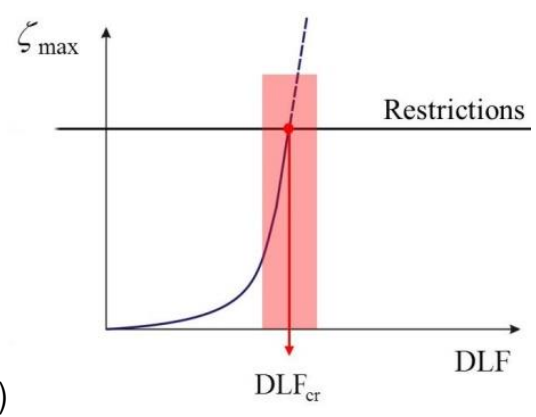

Fig. 3. The graphs of the dimensionless amplitude of deflection as a function of dynamic load factor DLF

Ari-Gur and Simonetta (1997) proposed four criteria. In this case, the dynamic buckling load was set as depending on deflection of the plate and load intensity defined as the force pulse amplitude or the shortening. They noted that for a perfectly plate, the pulse load, which would result in a loss of stability, was infinitely large.

A diversity of dynamic stability loss criteria follows from a lack of a generally accepted, accurate, explicit mathematical definition. One of a few exceptions, known to the authors, is the quasibifurcation criterion of dynamic buckling for step-like load (Heaviside's function) and the one concerning the critical pulse duration (so-called: the Kleiber-Kotula-Saran criterion (Kleiber et al., 1987)). This criterion was used at same papers: Kolakowski and Kubiak (2007), Kubiak (2007), Teter (2007, 2010, 2011), Teter and Kolakowski (2013). The latter criterion is based on a condition, that the tangent matrix of the system stiffness is zero. That is to say, all the Jacobian matrix are equal to zero.

Kubiak $(2007,2013)$ checked the values of the characteristic roots of the Jacobi matrix and proposed the dynamic buckling criterion that at the tracking time, the maximal radius calculated from the characteristic root of the Jacobi matrix was equal or greater than unity in the complex plane.

In the analysis of vibration the phase plane concept is often applied. Practically, the method of phase plane isn't used in the dynamic buckling. One can find only a few papers: Teter (2007, 2010, 2011), Hutchinson and Budiansky (1966), Hsu, (1967, 1968), Schokker et al. (1996) and monograph by Bazant and Cedolin (2010), which made use of the phase plane to determine the dynamic buckling load as an unbounded response for the uncoupled buckling. In the case of multimode buckling the method of phase plane was used in papers: Teter (2007, 2010, 2011), Teter and Kolakowski (2013). The phase plane criterion is formulated as: the dynamic buckling load for the tracing time of solutions has been defined as the minimum value of the pulse 
load, such that the phase portrait is an open curve. One should remember that phase planes for global buckling modes have a form of open and unbounded curves. The phase planes for local buckling modes have a form of open but bounded curve.

Petry and Fahlbusch (2000) were convince that the dynamic buckling load should be based on the stress state analysis. They have formulated the criterion of dynamic buckling as follows: the dynamic response of the structure is stable if the equivalent stress not exceed the assumed limit of stress.

\section{METHODS OF SOLUTION}

The differential equations of motion can be obtained from the Hamilton's Principle (Sridharan, 1983; Kolakowski and Kubiak, 2007; Kubiak, 2007; Teter, 2007, 2010, 2011, Teter and Kolakowski, 2013; Tamura and Babcock, 1975; Schokker et al., 1996). Basic dimensions of the plate (Fig. 4) are length parallel to the $x$ direction (denote as $l$ ), width $b$ (parallel to the $y$ direction). and thickness $h$ (parallel to the $z$ direction).

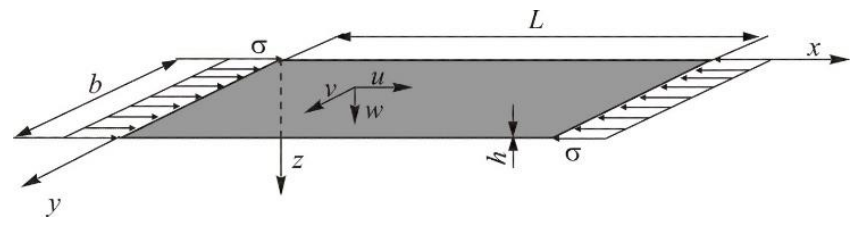

Fig. 4. The plate structure

In this case the Hamilton's Principle can be written as:

$\delta \Psi=\delta \int_{t_{0}}^{t_{1}} \Lambda d t=\delta \int_{t_{0}}^{t_{1}}(K-\Pi) d t=0$

where: $\Lambda$ is a Lagrange's function, $K$ is a kinetic energy, $\Pi$ is a total potential energy.

The total potential energy is equal to:

$\Pi=U-W=0.5 \int_{\Omega}\left(\sigma_{x} \varepsilon_{x}+\sigma_{y} \varepsilon_{y}+\tau_{x y} \gamma_{x y}\right) d \Omega$

$-\left\{\int_{0}^{b} h\left[p^{0}(y) u+\tau_{x y}^{0}(y) v\right] d y \mid \begin{array}{l}x=\ell \\ x=0\end{array}+\right.$

$\left.\int_{o}^{\ell} h\left[p^{0}(x) v+\tau_{x y}^{0}(x) u\right] d x \mid \begin{array}{l}y=b \\ y=0\end{array}+\int_{S} q w d S\right\}$

where: $p^{0}(x), p^{0}(y), \tau_{x y}^{0}(x), \tau_{x y}^{0}(y)$ are prebuckling in-plane load in the middle surface of the plate, $q$ is transverse load, $\Omega=l \times b \times h=S \times h$ is a volume of the plate and $u, v, w$ are components of the displacement in the $x, y, z$ directions, $\sigma_{x}, \sigma_{y}, \sigma_{z}$ and $\varepsilon_{x}, \varepsilon_{y}, \varepsilon_{z}$ are stress and strain in the $x, y, z$ directions, respectively.

The kinetic energy for the plate can be written as:

$$
K=0.5 \int_{\Omega} \rho\left(\tilde{u}_{, t t}^{2}+\tilde{v}_{, t t}^{2}+\widetilde{w}_{, t t}^{2}\right) d \Omega
$$

where: $\rho$ is density.

The kinematic conditions are assumed to be:

$$
\begin{aligned}
& \tilde{u}(x, y, z, t)=u(x, y, t)-z w_{, x}(x, y, t) \\
& \tilde{v}(x, y, z, t)=v(x, y, t)-z w_{, y}(x, y, t) \\
& \widetilde{w}(x, y, z, t) \equiv w(x, y, t)
\end{aligned}
$$

The energy variation can be written as: $\delta \Psi=\delta \int_{t_{0}}^{t_{1}} \Lambda d t=$

$\int_{t_{0}}^{t_{1}} \int_{\Omega} \rho\left(\tilde{u}_{, t} \delta \tilde{u}_{, t}+\tilde{v}_{, t} \delta \tilde{v}_{, t}+\widetilde{w}_{, t} \delta \widetilde{w}_{, t}\right) d \Omega d t+$

$+\int_{t_{0}}^{t_{1}} \int_{\Omega}\left(\sigma_{x} \delta \varepsilon_{x}+\sigma_{y} \delta \varepsilon_{y}+\tau_{x y} \delta \gamma_{x y}\right) d \Omega d t+$

$-\int_{t_{0}}^{t_{1}}\left\{\int_{0}^{b} h \quad\left[p^{0}(y) \delta u+\tau_{x y}^{0}(y) \delta v\right] d y \mid \begin{array}{c}x=\ell \\ x=0\end{array}+\right.$

$+\int_{o}^{\ell} h\left[p^{0}(x) \delta v+\tau_{x y}^{0}(x) \delta u\right] d x \mid \begin{aligned} & y=b \\ & y=0\end{aligned}+$

$\left.+\int_{S} q \delta w d S\right\} d t=0$ (Fig. 4):

Therese the middle surface strains and curvatures are equal

$\varepsilon_{x}^{b}=u_{, x}+\frac{1}{2}\left(w_{, x}^{2}+v_{, x}^{2}+u_{, x}^{2}\right)$

$\varepsilon_{y}^{b}=v_{, y}+\frac{1}{2} \quad\left(w_{, y}^{2}+u_{, y}^{2}+v_{, y}^{2}\right)$

$2 \varepsilon_{x y}^{b}=\gamma_{x y}^{b}=u_{, y}+v_{, x}+w_{, x} w_{, y}+u_{, x} u_{, y}+v_{, x} v_{, y}$

$\kappa_{x}=-w_{, x x} \quad \kappa_{\mathrm{y}}=-w_{, y y} \quad \kappa_{\mathrm{xy}}=-2 w_{, x y}$

In the majority of publications devoted to stability of structures, the terms $\left(\mathrm{v}_{, \mathrm{x}}^{2}+\mathrm{u}_{, \mathrm{x}}^{2}\right),\left(\mathrm{u}_{, \mathrm{y}}^{2}+\mathrm{v}_{, \mathrm{y}}^{2}\right)$ and $\left(\mathrm{u}_{, \mathrm{x}} \mathrm{u}_{\mathrm{y}} \mathrm{y}+\mathrm{v}_{\mathrm{,}, \mathrm{x}} \mathrm{v}_{\mathrm{y}}\right)$ are neglected for $\varepsilon_{\mathrm{x}}, \varepsilon_{\mathrm{y}}, \gamma_{\mathrm{xy}}=2 \varepsilon_{\mathrm{xy}}$, respectively, in the strain tensor components, Eqs. (6). When the full tensor of membrane strains: $\varepsilon_{\mathrm{xi}}, \varepsilon_{\mathrm{yi}}, \gamma_{\mathrm{xy}}=2 \varepsilon_{\mathrm{xy}}$ is taken into account, then an analysis of all buckling modes can be carried out. The main limitation that results from the adopted theory was the assumption of a linear dependence between the curvatures and the second order derivatives of the displacement $w$.

The differential equations of motion corresponding to Eqs. (6) for the one plate can be written as follows:

$N_{x, x}+N_{x y, y}+$

$\left\{\left(N_{x} u_{, x}\right)_{, x}+\left(N_{y} u_{, y}\right)_{, y}+\left(N_{x y} u_{, x}\right)_{, y}+\left(N_{x y} u_{, y}\right)_{, x}\right\}+$

$+\left[-h \rho_{0} u_{, t t}+h^{2} \rho_{1} w_{, x t t}\right]=0$

$N_{x y, x}+N_{y, y}+$

$\left\{\left(N_{x} v_{, x}\right)_{, x}+\left(N_{y} v_{, y}\right)_{, y}+\left(N_{x y} v_{, x}\right)_{, y}+\left(N_{x y} v_{, y}\right)_{, x}\right\}+$

$+\left[-h \rho_{0} v_{, t t}+h^{2} \rho_{1} w_{, y t t}\right]=0$

$M_{x, x x}+M_{y, y y}+2 M_{x y, x y}+q+$

$\left(N_{x} w_{, x}\right)_{, x}+\left(N_{y} w_{, y}\right)_{, y}+\left(N_{x y} w_{, x}\right)_{, y}+$

$+\left(N_{x y} w_{, y}\right)_{, x}+\left[-h \rho_{o} w_{, t t}-h^{2} \rho_{1}\left(u_{, x t t}+v_{, y t t}\right)\right.$

$\left.+h^{3} \rho_{2}\left(w_{, x x t t}+w_{, y y t t}\right)\right]=0$

In the static case, the dynamic components of Eqs. (7) are neglected.The solution of these equations for each plate should satisfy: initial conditions, kinematic and static continuity conditions at the junctions of adjacent plates and the boundary conditions. The effects of damping can be neglected in practice. Its influence on the dynamic response is not greater than $1 \%$. Kounadis et al. (1997) used a damper in their model and analyzed the damping influence on the dynamic response. The presented solution showed that the difference in the results for the structure with viscous Rayleigh damping and without damping was $0.2 \%$. Additionally, wave propagation and in-plane effects can be neglected in the dynamic buckling study. The non-linear problem of stability has been solved with the asymptotic perturbation method in order to obtain an approximate analytical solution to the equations. The displacement fields and the sectional force fields were expanded in power series in the amplitudes of the buckling modes divided by the thickness of the first component plate. By substituting the 
displacement fields and the sectional force fields into the equations of equilibrium, junction conditions and boundary conditions, the boundary value problems of the zero, first and second order can be obtained.

The displacements fields and the sectional force fields were defined as fallowed:

$$
\begin{gathered}
\mathbf{U}=\lambda \mathbf{U}^{(0)}+\zeta_{i} \mathbf{U}^{(i)}+\zeta_{i} \zeta_{j} \mathbf{U}^{(i j)}+\zeta_{i} \zeta_{j} \zeta_{k} \mathbf{U}^{(i j k)}+\cdots, \\
\mathbf{N}=\lambda \mathbf{U}^{(0)}+\zeta_{i} \mathbf{U}^{(i)}+\zeta_{i} \zeta_{j} \mathbf{U}^{(i j)}+\zeta_{i} \zeta_{j} \zeta_{k} \mathbf{U}^{(i j k)}+\ldots,
\end{gathered}
$$

The range of indexes was $(l, N)$. The summation was supposed on the repeated indexes.

The differential equations of motion can be written as:

$$
\begin{aligned}
& \frac{1}{\omega_{o r}^{2}} \zeta_{r, t t}(t)+\left(1-\frac{\sigma(t)}{\sigma_{r}}\right) \cdot \zeta_{r}(t)+ \\
& +a_{i j r} \zeta_{i}(t) \zeta_{j}(t)+b_{r r r r} \zeta_{r}^{3}(t)+\ldots=\zeta_{r}^{*} \frac{\sigma(t)}{\sigma_{r}}
\end{aligned}
$$

for $r=1, \ldots, N$, where: $\zeta_{r}$ - the dimensionless amplitude of the $r$ th buckling mode (the maximum deflection referred to the thickness of the first plate), $\sigma_{r}, \omega_{o r}, \zeta_{r}^{*}-$ the critical stress, the natural frequency of free vibrations and the dimensionless amplitude of the initial deflection corresponding to the $r$-th buckling mode, respectively, $\sigma$ - the compressive stress. The coefficients: $a_{i j r}, b_{r r r r}$ were determined with well-known formulae (see for example: Byskov and Hutchinson (1977), Kubiak (2013), Byskov (1988), Kolakowski et al. (1999), Teter and Kolakowski (2004)).

In Eqs. (9), the omission of the coefficients $b_{i j k r}$ corresponding to the second order mixed mode was possible, because the post-buckling coefficients $a_{i j r}$ (a three-mode approach) have been already included in the analysis. The secondary local buckling modes were analogous to the second order mixed modes. The admissibility of neglecting the mixed mode has been shown. In the static case, the dynamic components of Eqs. (9) were neglected.

For the ideal structure, the initial imperfections are equal to zero (in Eqs. (9) $-\zeta_{\mathrm{r}}^{*}=0$ ) and for the uncoupled problem, all indexes: i, j, r are equal to 1 . The initial conditions were assumed that the no-dimensional displacements and velocities were equal to zero.

The static system of ordinary differential equations of equilibrium was solved by the modified numerical transition matrix method, in which the state vector of the final edge is derived from the state vector of the initial edge by the numerical integration of the differential equations along the circumferential direction formulae by means of the Godunov orthogonalization method. This method has allowed to find the post-buckling coefficients which can be used in description of post-buckling equilibrium path for static load and in Lagrange equations for dynamic load. Having Lagrange equations it's possible to analyze the transient dynamic response of thin-walled structures subjected to pulse loading. What is important using this method one can solve static simultaneous buckling problem as well as the dynamic one (Kubiak, 2013). The static interactive buckling of thin-walled structures have been discussed in the papers Kolakowski and co-workers (1987a, 1987b, 1988, 1989a, 1989b, 1993a, 1993b, 1995, 1996, 1999, $2000,2002,2003,2004,2005)$. The thin-walled closed and open (Fig. 5b) cross sections columns with or without stiffeners under compression were considered in detail. The columns were long and prismatic. The both ends were simple supported (Fig. 5a). The structures were composed of rectangular plates interconnected along longitudinal edges. In this case, a plate model was adopted in the analysis (Fig. 5c). The material of the structure was defined as isotropic, orthotropic or laminate. (a)

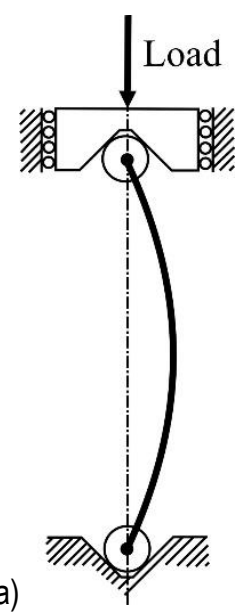

(d)

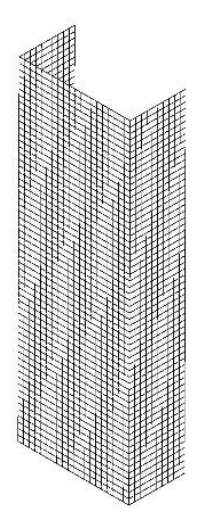

(b)
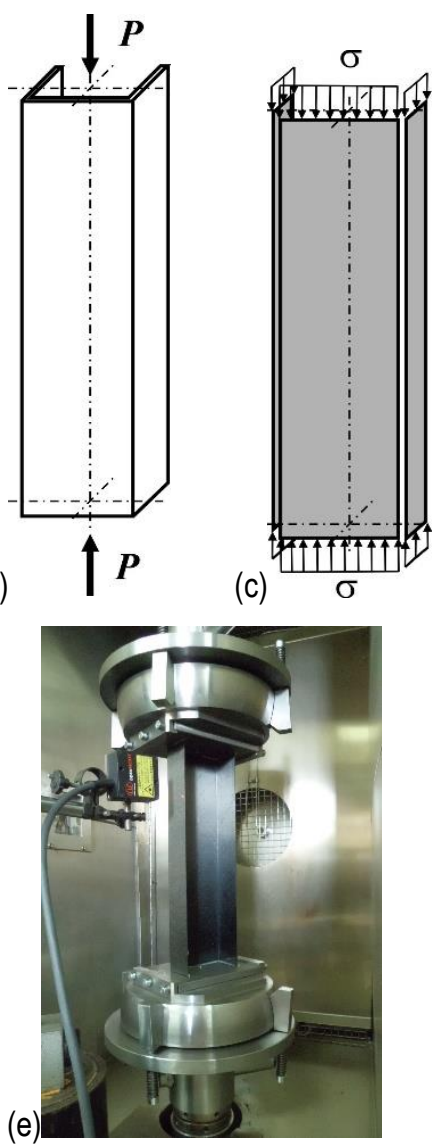

Fig. 5. Modelling of buckling thin-walled structure: (a) physical model;

(b) calculation model; (c) ANM model; (d) FEM model;

(e) experimental model

In the papers Teter and Kolakowski $(2004,2005)$, the static interactive buckling of columns with open sections, reinforced with intermediate stiffeners and with edge reinforcements, has been considered. The results discussed in the studies (Teter and Kolakowski, 2004) represent the most important results obtained by the authors in earlier investigations devoted to central intermediate stiffeners. Intermediate stiffeners are widely used in many types of structures. These stiffeners carry a portion of loads and subdivide the plate element into smaller sub-elements, thus increasing considerably the load carrying capacity. The shape, size and position of intermediate stiffeners and edge stiffeners in thinwalled structures exert a strong influence on the stability and the post-buckling behaviour of thin-walled structures. The importance of the minimum rigidity of the intermediate stiffeners required to restrict buckling to the plate elements was studied. The proposed estimation of the structure load carrying capacity for the second order approximation (Teter and Kolakowski, 2005) on the basis of the linear analysis complies with the FEM with the maximum error equaled to $25 \%$ in the whole over-critical range of the shortening. The method of determining the value of the frequencies of free vibrations was presented in the paper (Teter and Kolakowski, 2003). The buckling modes were the same as the vibration modes, so the solution to the eigenvalue problem is searched for various values of the $r-$ th harmonic. For the free vibration, the axial load is equal to zero. At the point where the static load parameter reaches its maximum value for the imperfect structure 
(secondary bifurcation or limit points), the Jacobian of the nonlinear static system was equal to zero.

The problem of interactive dynamic buckling can be solved by means of the Runge-Kutta numerical method with differentiation formulas of variable order. The calculations were carried out for a settled imperfections (Kolakowski and Kubiak, 2007; Kubiak, 2007; Teter, 2007, 2010, 2011, Teter and Kolakowski, 2013; Tamura and Babcock, 1975; Kolakowski, 2009).

Computer codes to determine the post-buckling equilibrium paths within the second order approximation for structures made of isotropic, orthotropic materials, including orthotropy that varies along the plate width, gradient materials have been developed (Kolakowski (1987a, 1987b, 1988, 1989a, 1989b, 1989c, 1993a, 1993b, 1996). The codes has allowed to employ the analyticalnumerical method to analyze elastic stability in thin-walled structures simply supported at both ends. Cases of complex loading of the structure and boundary reinforcements and changes in the plate thickness along its width can be analyzed. To extend the computing possibilities of this method, subroutines have been developed for determination of free vibration frequencies of thinwalled structures, taking into consideration all the inertia forces, including tangent and rotational inertia forces (Kolakowski and Kubiak, 2005). The presented analytical-numerical method provides very effective solutions to various types of thin-walled structures and it enables the statics and dynamic analysis of stability. It allows to analyze a dynamic response of complex thin-walled structures subjected to various shapes of the pulse loading and to calculate the critical dynamic buckling value using different dynamic buckling criteria. The analysis of dynamic stability with the analytical-numerical method renders the modal analysis of coupled and uncoupled dynamic buckling of thin-walled structures possible.

In the monograph by Kubiak (2013) has been analyzed a dynamic response of thin-walled structures under pulse loading, obtained with the finite elements method (the so-called: FEM) and, which should be noticed, with the ANM as well. The FEM has been used as a method to verify the calculations conducted with the ANM (Fig. 5c).

An application of finite elements method allows for analysis of nonlinear stability under static and dynamic loads in whole range. In order to analyze the post-buckling behaviour of the structure, calculations should be made in two stages. The linear analysis of buckling should be carried out in the first step in order to determine a few buckling modes that correspond to the lowest values of critical loads, both for local and global modes. Lanczos eigenvalue extraction methods can be used (Kirsch, 2004). In the second step, the non-linear analysis of stability for the model, in which the initial shape imperfections corresponding to the lowest modes of buckling are assumed, should be conducted. In case of the non-linear analysis of interactive buckling, the imperfections in shape corresponding to different buckling modes are assumed. Quite a serious problem lies in determination of the magnitude of imperfections for various modes in such a way that the relation between these imperfections should reflect the effect of one buckling mode on the other one (Kolakowski and Kubiak, 2005). A very important role in obtaining correct results is played by the proper modelling of boundary conditions. Modelling of boundary conditions, which correspond to the conditions assumed in other calculation methods (e.g., analytical models or analytical-numerical ones), is particularly difficult. The structural dynamic analysis using FEM, which has allowed us to find the response of a structure to the pulse loading, has been conducted using the New- mark's formula for the time integration and the Newton-Raphson scheme or arc-length method (Madenci and Guven, 2006; Morris, 2008). The applications of finite element method FEM to solve interaction buckling problems are on-going. FEM proved to be the most successful numerical method to analyze static or dynamic buckling of complex thin-walled structures. Such analyses involve a discretization of the structure and nonlinear solutions of large equation system. This method is very important in practice, because it is becoming standard practice to use FEM in conjunction with experiments in improving and preparing new engineering standards for thin-walled structures. Early 1970s papers (Barsoum and Gallagher, 2009; Powell and Klinger, 1970) described elastic global buckling using beam elements. The bifurcation analysis is described in papers (Rajasekaran and Murray, 1973; Toneff et al., 1987). The FEM plate models using plate or shell elements permitted analyses of coupling between local and global bucking in the elastic range (Bradford, 1990). There is no distinction between the analyses of plate and shell structures. In both case one can use shell elements in geometric and material nonlinear analyses (Lee et al., 1979, 1984; Dvorkin and Bathe, 1984; Fafard et al., 1987; White and Abel, 1990).

The finite element method was used by Bao et al. (1997) to analyze the critical stress for the plates and beam-columns made of anisotropic materials. Barbero and Tomblin (1993) dealt with a loss of global stability of thin-walled I-section beamcolumns made of various fibre composites. Authors compared the experimental results with the FEM ones receiving a very good agreement. Gupta and Rao (1985) studied the stability of a thin cantilever beam with a Z-cross-section made of two (45/-45) or three- $(0 / 45 / 0)$ layered laminates. The authors employed the finite element method and used two-node beam elements with three degrees of freedom at each node to build a discrete model of the beam under analysis.

Cui et al. $(1999,2002)$ presented the results of experimental results for rectangular plates with different boundary conditions subjected to pulse load. The authors performed a numerical analysis using the finite element method (Abaqus system). For the numerical analysis, they assumed that the dynamic critical load in the elastic-plastic range increased with an increasing material strengthening curve in the elastic-plastic state.

The experimental investigations on stability of thin-walled structures were presented in papers: Put et al. (1999), Hancock (2003), Kwon et al. (2007), Becque and Rasmusen (2009), Magnucka-Blandzi et al. (2012), Magnucki et al. (2010), Debski (2013). The experimental investigations of stability and carrying capacity if thin-walled box-sections beams (Krolak and Mlotkowski, 1996) and thin-walled multi-cell columns were made by Krolak et al. (2007). The results of FEM calculations have been compared to the theoretical and experimental investigations. Some composite structures were also taken into account (Debski, 2013; Turvey and Zhang, 2006; Wong and Wang, 2007; Parlapalli et al., 2007; Debski et al., 2013a, 2013b). A more experimental papers can be found in review papers: Chou and Rhodes (1997), Singer et al. (1998, 2002), Magnucka-Blandzi et al. (2011). Magnucki with his team (Magnucka-Blandzi and Magnucki, 2011) analyzed global and local stability of cold-formed thin-walled channel beams with open or closed cross-sections. The numerical FEM analysis and the laboratory tests of selected beams were performed. The numerical investigations of the optimization problem have been carried out. 


\section{FINAL REMARKS}

The analytical-numerical method (ANM) provides very effective solutions to various types of thin-walled structures and it enables the dynamic analysis of buckling. It allows one to analyse a dynamic response of complex thin-walled structures subjected to various shapes of the pulse loading and to calculate the critical dynamic buckling value using different dynamic buckling criteria. The analysis of dynamic stability with the analyticalnumerical method renders the modal analysis of coupled and uncoupled dynamic buckling of thin-walled structures possible.

The most important advantage of this analytical-numerical method is that it enables to describe a complete range of behaviour of thin-walled structures from all global (i.e., flexural, flexuraltorsional, distortional bucklings and their combinations) to the local stability. In the solution obtained, a shear lag phenomenon, an effect of cross-sectional distortions, as well as an interaction between all the walls of structures are included.

Attention should be paid to the fact that the results obtained from the ANM are attained much faster and are less laborious if compared to the results from the FEM, and are characterized by satisfactory accuracy. Due to the application of the FEM, it has been possible to verify the results and moreover, to visualize better the results. Because the results obtained by both the methods are similar, it can be said that the proposed analyticalnumerical method yields proper results.

\section{REFERENCES}

1. Ali M.A., Sridharan S. (1988), A versatile model for interactive buckling of columns and beam-columns, International Journal of Solids and Structures, Vol. 24, 481-486.

2. Ari-Gur J., Simonetta S.R. (1997), Dynamic pulse buckling of rectangular composite plates, Composites Part B, Vol. 28B, 301-308.

3. Bangash M.Y.H. (2009), Shock. impact and explosion, Structural analysis and design, Springer, Verlag, New York, USA.

4. Bao G., Jiang W., Roberts J.C. (1997), Analytic and finite element solutions for bending and buckling of orthotropic rectangular plates, Int J Solid Struct, Vol. 34, No. 14, 1797-1822.

5. Barbero E., Tomblin J. (1993), Euler buckling of thin-walled composite columns, Thin-Walled Structures, Vol. 17, 237-258.

6. Barbero E.J., Madeo A., Zagari G., Zinno R., Zucco G. (2014), Koiter asymptotic analysis of folded laminated composite plates, Composites Part B: Engineering, Vol.61, 267-274.

7. Barsoum R.S., Gallagher R.H. (2009), Finite element analysis of torsional and torsional-flexural stability problems, Int. Journal for Numerical Methods in Engineering, Vol. 2, 335-352.

8. Bazant Z.P., Cedolin L. (2010), Stability of Structures. Elastic. Inelastic. Fracture and Damage Theories, Oxford University Press, UK.

9. Becque J., Rasmusen K.J.R. (2009), Experimental investigation of local-overall interaction buckling of stainless steel lipped channel columns, J. Constructional Steel Research, Vol. 65, 1677-1684.

10. Benito R., Sridharan S. (1985), Mode interaction in thin-walled structural members, Journal of Structural Mechanics, Vol. 12, 517542.

11. Benito R., Sridharan S. (1985). Interactive buckling analysis with finite strips, International Journal for Numerical Methods in Engineering, Vol. 21,145-161.

12. Bradford M.A. (1990), Lateral-distortional buckling of tee-section beams, Thin-Walled Structures, Vol. 10,13-30.

13. Budiansky B. (1966), Dynamic buckling of elastic structures: criteria and estimates. Report SM-7, NASA CR-66072, USA.
14. Budiansky B. (1966), Survey of some buckling problem. AIAA Journal, Vol. 4, 1505-1510.

15. Byskov E. (1979), Applicability of an asymptotic expansion for elastic buckling problems with mode interaction, AIAA Journal, Vol. 17, 630-633.

16. Byskov E. (1988), Elastic buckling problem with infinitely many local modes, Mechanics of Structures and Machines, Vol. 15, 413-435.

17. Byskov E., Hutchinson JW. (1977), Mode interaction in axially stiffened cylindrical shells, AIAA Journal, Vol.15, 941-48.

18. Casciaro R., Garcea G., Attanasio G., Giordano F. (1998), Pertubative approach to elastic post-buckling analysis, International Journal of Computer \& Structure, Vol. 66, 585-595.

19. Chou S.M., Rhodes J. (1997), Review and compilation of experimental results on thin-walled structures. Computers \& Structures, Vol. 65 No. 1, 47-67.

20. Cui S., Cheong H.K., Hao H. (1999), Experimental study of dynamic buckling of plates under fluid-solid slamming. International Journal of Impact Engineering, Vol. 22, 675-691.

21. Cui S., Hao H., Cheong H.K. (2002), Theoretical study of dynamic elastic buckling of columns subjected to intermediate velocity impact loads, International Journal of Mechanical Science, Vol. 44, 687-702.

22. Debski H. (2013), Experimental investigation post-buckling behaviour of composite column with top-hat cross section, Maintenance and Reliability, Vol. 2, 105-109.

23. Debski H., Kubiak T., Teter A. (2013a), Buckling and postbuckling behaviour of thin-walled composite channel section column", Composite Structures Vol. 100, 195-204.

24. Debski H., Kubiak T., Teter A. (2013b), Experimental investigation of channel-section composite profiles' behaviour with various sequences of plies subjected to static compression, Thin-Walled Structures, Vol. 71, 147-154.

25. Dvorkin E.N., Bathe KJ. (1984), A continuum mechanics based four-node shell element for general nonlinear analysis, Engineering Computations, Vol. 1, 77-88.

26. Fafard M., Beauleu D., Dhatt C. (1987), Buckling of thin-walled members by finite elements, Computers and Structures, Vol. 25, 183-190.

27. Garcea G., Madeo A., Zagari G. and Casciaro R. (2009), Asymptotic post-buckling FEM analysis using correlational formulation, International Journal of Solids and Structures, Vol. 46, 377-397.

28. Garcea G., Salerno G., Casciaro R. (1999), Sanitizing of locking in Koiter perturbation analysis through mixed formulation, Computer Methods in Applied Mechanics and Engineering, Vol. 180,137-167.

29. Gilat R., Aboudi J. (1995), Dynamic buckling of nonlinear resin matrix composite structures, Composite Structures, Vol. 32, 81-88.

30. Goltermann P., Mollman H. (1989), Interactive buckling in thinwalled beams - II. Applications, International Journal of Solids and Structures, Vol. 25, 729-749.

31. Gupta R.K., Rao K.P. (1985), Instability of laminated composite thinwalled open-section beams, Composite Materials, Vol. 4, 299-313.

32. Hancock G.J. (2003), Cold-formed steel structures, J. Constructional Steel Research, Vol. 59, 473-487.

33. Hsu C.S. (1967), The effects of various parameters on the dynamic stability of shallow arch, Journal of Applied Mechanics, Vol. 34, 349-356.

34. Hsu C.S. (1968), On dynamic stability of elastic bodies with prescribed initial conditions, International Journal of Non-Linear Mechanics, Vol. 4, 1-21.

35. Hutchinson J.W., Budiansky B. (1966), Dynamic buckling estimates, AIAA Journal, Vol. 4, 525-530.

36. Kappos AJ. Dynamic Loading and Design of Structures, Spon Press, Taylor \& Francis Group, 2002.

37. Kirsch U. (2004), Design-oriented Analysis of Structures, Unified Approach. Kluwer Academic Publishers, USA.

38. Kleiber M., Kotula W., Saran M. (1987), Numerical analysis of dynamic quasi-bifurcation, Engineering Computations Vol. 4, 48-52.

39. Koiter WT. (1976), General theory of mode interaction in stiffened plate and shell structures, WTHD Report 590, Delft. 
40. Koiter W.T., Pignataro M. (1974), An alternative approach to the interaction between local and overall buckling in stiffened panels, Buckling of Structures/Proceedings of IUTAM Symposium. Cambridge, 133-148.

41. Kolakowski Z. (1987a), Mode interaction in thin-walled trapezoidal column under uniform compression, Thin-Walled Structures, Vol. 5, 329-342.

42. Kolakowski Z. (1987b), Mode interaction in wide plate with closed section longitudinal stiffeners under compression, Engineering Transactions, Vol. 35, 591-609.

43. Kolakowski Z. (1988), Some aspects of mode interaction in thinwalled stiffened plate under uniform compression, Engineering Transactions, Vol. 36, 167-179.

44. Kolakowski Z. (1989a), Interactive buckling of thin-walled beams with open and closed cross-section, Engineering Transactions, Vol. 37, 375-397.

45. Kolakowski Z. (1989b), Mode interaction in wide plate with angle section longitudinal stiffeners under compression, Engineering Transactions, Vol. 37, 117-135.

46. Kolakowski Z. (1989c), Some thoughts on mode interaction in thinwalled columns under uniform compression. Thin-Walled Structures, Vol. 7, 23-35.

47. Kolakowski Z. (1993a), Influence of modification of boundary conditions on load carrying capacity in thin-walled columns in the second order approximation, International Journal of Solids and Structures, Vol. 30, 2597-2609.

48. Kolakowski Z. (1993b), Interactive buckling of thin-walled beams with open and closed cross-sections, Thin-Walled Structures, Vol. $15,159-183$.

49. Kolakowski Z. (1996), Semi-analytical method for the analysis of the interactive buckling of thin-walled elastic structures in the second order approximation, International Journal of Solids and Structures, Vol. 33, 3779-3790.

50. Kolakowski Z. (2007), Some aspects of dynamic interactive buckling of composite columns, Thin-Walled Structures, Vol. 45, 866-871.

51. Kolakowski Z. (2009), Static and dynamic interactive buckling of composite columns, Journal of Theoretical and Applied Mechanics, Vol. 47, 177-192.

52. Kolakowski Z. Mania R.J. (2013), Semi-analytical method versus the FEM for analyzing of the local post-buckling of thin-walled composite structures, Composite Structures, Vol. 97, 99-106.

53. Kolakowski Z., Krolak M. (1995), Interactive elastic buckling of thinwalled closed orthotopic beam-columns, Engineering Transactions, Vol. 43, 571-590.

54. Kolakowski Z., Krolak M. (2002), Modal coupled instabilities of thinwalled composite plate and shell structures, Composite Structures, Vol. 76, 303-313.

55. Kolakowski Z., Krolak M., Kowal-Michalska K. (1999), Mode interactive buckling of thin-walled composite beam-columns regarding distortional deformations, International Journal of Engineering Sciences, Vol. 37, 1577-1596.

56. Kolakowski Z., Kubiak T. (2005), Load-carrying capacity of thinwalled composite structures, Composite Structures, Vol. 67, 417426.

57. Kolakowski Z., Kubiak T. (2007), Interactive dynamic buckling of orthotropic thin-walled channels subjected to in-plane pulse loading, Composite Structures, Vol. 81, 222-232.

58. Kolakowski Z., Teter A. (1995), Influence of local postbuckling behaviour on bending of thin-walled elastic beams with central intermediate stiffeners, Engineering Transactions, Vol. 43, No. 3, 383-396.

59. Kolakowski Z., Teter A. (1995), Interactive buckling of thin-walled closed elastic column-beams with intermediate stiffeners, International Journal of Solid and Structures, Vol. 32, 1501-1516.

60 . Kolakowski Z., Teter A. (2000), Interactive buckling of thin-walled beam-columns with intermediate stiffeners or/and variable thickness, International Journal of Solid and Structures, Vol. 37, 3323-3344.
61. Kounadis A.N., Gantes C., Simitses G. (1997), Nonlinear dynamic buckling of multi-dof structural dissipative system under impact loading, International Journal Impact Engineering, Vol. 19, 63-80.

62. Krolak M., Kowal-Michalska K., Mania R.J., Swiniarski J. (2007), Experimental tests of stability and load carrying capacity of compression thin-walled multi-cell columns of triangular crosssection, Thin-Walled Structures, Vol. 45, 883-887.

63. Krolak M., Mlotkowski A. (1996), Experimental analysis of postbuckling and collapse behaviour of thin-walled box-section beam, Thin-Walled Structures, Vol. 26, 287-314.

64. Kubiak T. (2007), Criteria of dynamic buckling estimation of thinwalled structures, Thin-Walled Structures, Vol. 45, 888-892.

65. Kubiak T. (2013), Static and dynamic buckling of thin-walled plate structures, Springer Verlag, London, UK.

66. Kwon Y.B., Kim B.S., Hancock G.J. (2007), Compression tests of high strength cold-formed steel channels with buckling interaction, $J$. Constructional Steel Research, Vol. 63, 1590-1602.

67. Lee H.P., Harris P.J. (1979), Post-buckling strength of thin-walled members, Computers and Structures, Vol. 10,689-702.

68. Lee H.P., Harris P.J., Cheng-Tzu T.H. (1984), A nonlinear finite element computer program for thin-walled member, Thin-Walled Structures, Vol. 2, 355-376.

69. Lindberg H.E. (ed.) (1987), Dynamic pulse buckling, Kluwer Academic Publishers.

70. Madenci E., Guven I. (2006), The finite element method and applications in engineering using ANSYS. Springer, Verlag, New York, USA.

71. Magnucka-Blandzi E., Magnucki K. (2011), Buckling. and optimal design of cold-formed thin-walled beams: Review of selected problems, Thin-Walled Structures, Vol. 49, 554-561.

72. Magnucka-Blandzi E., Paczos P., Wasilewicz P. (2012), Buckling study of thin-walled channel beams with double box-flanges in pure bendin, Strain, Vol. 48, No. 4, 317-325.

73. Magnucki K., Paczos P., Kasprzak J. (2010), Elastic buckling of cold-formed thin-walled channel beams with drop flanges, Journal of Structural Engineering, Vol. 136, No. 7, 886-96.

74. Manevich Al. (1981), Interaction of buckling modes of stiffened plate under compression, Stroitelnaya Mekhanika i Raschet Sooruzhenii, Vol.1, 24-29.

75. Manevich Al. (1982), Theory of interaction buckling of stiffened thinwalled structures, Prikladnaya Matematika i Mekhanika, Vol.46, 337-345.

76. Manevich Al. (1985), Stability of shells and plates with T-section stiffeners, Stroitelnaya Mekhanika i Raschet Sooruzhenii, Vol. 2, 3 4-38.

77. Manevich Al. (1988), Interactive buckling of stiffened plate under compression, Mekhanika Tverdogo Tela, Vol. 5, 152-159.

78. Mania R. (2005), Buckling analysis of trapezoidal composite sandwich plate subjected to in-plane compression, Composite Structures, Vol. 69, 482-490.

79. Mania R., Kowal-Michalska K. (2007), Behaviour of composite columns of closed cross-section under in-plane compressive pulse loading, Thin-Walled Structures, Vol. 45, 902-905.

80. Moellmann H. and Goltermann P. (1989), Interactive buckling in thinwalled beams; Part I: Theory; Part II: Applications, Inter. Journal of Solids and Structures, Vol. 25, 715-749.

81. Morris A. (2008), Practical guide to reliable finite element modelling. John Wiley\&Sons Inc, USA.

82. Niezgodzinski T., Kubiak T. (2005), The problem of stability of web sheets in box-girders of overhead cranes, Thin-Walled Structures Vol. 43, 1913-1925.

83. Parlapalli M.R., Soh K.C., Shu D.W., Ma G. (2007), Experimental investigation of delamination buckling of stitched composite laminates, Composites: Part A; Vol. 38, 2024-2033.

84. Petry D. and Fahlbusch G. (2000), Dynamic buckling of thin isotropic plates subjected to in-plane impact, Thin-Walled Structures Vol. 38, 267-283. 
85. Pignataro M., Luongo A. (1987), Asymmetric interactive buckling of thinwalled columns with initial imperfection, Thin-Walled Structures, Vol. 3, 365-386.

86. Pignataro M., Luongo A. (1987), Multiple interactive buckling of thin-walled members in compression, Proceedings of the International Colloq. on Stability of Plate and Shell Structures. University Ghent, 235-240.

87. Pignataro M., Luongo A., Rizzi N. (1985), On the effect of the local overall interaction on the postbuckling of uniformaly compressed channels, Thin-Walled Structures, Vol. 3, 283-321.

88. Powell G., Klinger R. (1970) Elastic lateral buckling of steel beams, Journal of Structural Engineering ASCE, Vol. 96, No. 9, 1919-1932.

89. Put B.M., Pi Y.L., Trahair N.S. (1999), Lateral buckling test on coldformed channel beams, Journal of Structural Engineering ASCE, Vol. 125 , No. 5, 532-539.

90. Rajasekaran S., Murray D.W. (1973), Coupled local buckling in wide flange beam columns, Journal of Structural Engineering ASCE 1973:99(6):1003-23.

91. Schokker A., Sridharan S., Kasagi A. (1996), Dynamic buckling of composite shells. Computers and Structures, Vol. 59, 43-55.

92. Simitses G.J. (1990), Dynamic stability of suddenly loaded structures, Springer Verlag, New York, USA.

93. Simitses G.J., Hodges D.H. (2006), Fundamentals of structural stability, Butterworth-Heinemann, USA.

94. Singer J., Arbocz J., Weller T. (1998), Buckling experiments. experimental methods in buckling of thin-walled structure. Basic concepts. columns. beams and plates, Vol. 1, John Wiley \& Sons Inc., New York, USA.

95. Singer J., Arbocz J., Weller T. (2002), Buckling experiments. experimental methods in buckling of thin-walled structure. shells built-up structures. Composites and additional topics, Vol. 2, John Wiley \& Sons Inc., New York, USA.

96. Sridharan S. (1983), Doubly symmetric interactive buckling of plate structures, International Journal of Solids and Structures, Vol. 19, 625-641.

97. Sridharan S., Ali M.A. (1985), Interactive buckling in thin-walled beam-columns, Journal of Engineering Mechanics, ASCE, Vol. 111, 1470-1486.

98. Sridharan S., Ali M.A. (1986), An improved interactive buckling analysis of thin-walled columns having doubly symmetric sections, International Journal of Solids and Structures, Vol. 22, 429-443.

99. Sridharan S., Benito R. (1984), Columns static and dynamic interactive buckling, Journal of Engineering Mechanics, ASCE, Vol. $110,49-65$.

100. Stronge W.J. (2000), Impact mechanics, Cambridge University Press, Cambridge, New York, USA.

101. Tamura Y.S., Babcock C.D. (1975), Dynamic stability of cylindrical shell under step loading, Journal of Applied Mechanics, Vol. 42, 190-194.

102. Teter A. (2007), Static and dynamic interactive buckling of isotropic thin-walled closed columns with variable thickness, Thin-Walled Structures, Vol. 45, 936-940.

103. Teter A. (2010), Dynamic. multimode buckling of the thin-walled columns with subjected to in-plane pulse loading, Inter. J. NonLinear Mechanics, Vol. 45, 207-218.

104. Teter A. (2011), Dynamic critical load based on different stability criteria for coupled buckling of columns with stiffened open crosssections, Thin-Walled Structures, Vol. 49, 589-595.
105. Teter A., Kolakowski Z. (2003), Natural frequencies of thin-walled structures with central intermediate stiffeners or/and variable thickness, Thin-Walled Structures Vol. 41, 291-316.

106. Teter A., Kolakowski Z. (2004), Interactive buckling and load carrying capacity of thin-walled beam-columns with intermediate stiffeners, Thin-Walled Structures, Vol. 42, 211-254.

107. Teter A., Kolakowski Z. (2005), Buckling of thin-walled composite structures with intermediate stiffeners, Composite Structures Vol. $69,421-428$.

108. Teter A., Kolakowski Z. (2013), Coupled dynamic buckling of thinwalled composite columns with open cross-sections, Composite Structures, Vol.95, 28-34.

109. Thompson J.M.T., Hunt G.W. (1973), General Theory of Elastic Stability, Wiley, New York, USA.

110. Toneff J.D., Stiemer S.F. and Osterrieder P. (1987), Local and overall buckling in thin-walled beams and columns. Journal of Structural Engineering ASCE, Vol. 113, No. 4, 769-786.

111. Turvey G.J., Zhang Y. (2006), A computational and experimental analysis of the buckling. postbuckling and initial failure of pultruded GRP columns, Computers \& Structures, Vol. 84, 1527-1537.

112. Tvergaard V. (1973), Imperfections sensitivity of a wide integrally stiffened panel under compression, International Journal of Solids and Structures, Vol. 9,177-192.

113. Tvergaard V. (1973), Influence of post-buckling behaviour on optimum design of stiffened panels, International Journal of Solids and Structures, Vol. 9, 1519-34.

114. van der Heijden A.M.A. (ed.) (2009), WT. Koiter's elastic stability of solids and structures, Cambridge University Press, UK.

115. Virgin L.N. (2007), Vibration of axially loaded structures, Cambridge University Press, UK

116. Volmir S.A. (1972), Nonlinear dynamics of plates and shells, Science, Moscow, Russia.

117. Warminski J., Teter A. (2012), Non-linear parametric vibrations of a composite column un-der uniform compression, Proceedings of the Institution of Mechanical Engineers. Part C: Journal of Mechanical Engineering Science, Vol. 226, 1921-1938.

118. Weller T., Abramovich H., Yaffe R. (1989), Dynamic buckling of beams and plates subjected to axial impact, Composite Structures, Vol. 37, 835-851.

119. White D.W., Abel J.F. (1990), Accurate and efficient nonlinear formulation of a nine-node shell element with spurious mode control, Computers and Structures, Vol. 35, 621-641.

120. Wong P.M.H., Wang Y.C. (2007), An experimental study of pultruded glass fibre reinforced plastics channel columns at elevated temperatures, Computers \& Structures, Vol. 81, 84-95.

121. Zhang T., Liu T., Zhao Y. (2004), Nonlinear dynamic buckling of stiffened plates under in-plane impact load, Journal of Zheijang University Science, Vol. 5, 609-617.

Acknowledgements: This paper was financially supported by the Ministerial Research Project No. DEC-2013/11/B/ST8/04358 financed by the Polish National Science Centre. 